Abstract

\title{
Feasibility to Detect Natural Frequencies of Hydraulic Turbines under Operation Using Strain Gauges ${ }^{+}$
}

\author{
David Valentin *, Alexandre Presas, Matias Bossio, Mònica Egusquiza, Eduard Egusquiza and \\ Carme Valero \\ Centre de Diagnòstic Industrial i Fluidodinàmica (CDIF), Universitat Politècnica de Catalunya (UPC), \\ Barcelona 08028, Spain; alexandre.presas@upc.edu (A.P.); matias.alberto.bossio@upc.edu (M.B.); \\ monica.egusquiza@upc.edu (M.E.); eduard.egusquiza@upc.edu (E.E.); m.del.carmen.valero@upc.edu (C.V.) \\ * Correspondence: david.valentin@upc.edu \\ † Presented at the 5th International Symposium on Sensor Science (I3S 2017), Barcelona, Spain, 27-29 \\ September 2017.
}

Published: 6 December 2017

Nowadays, hydropower plays an essential role in the energy market. Due to its fast response and regulation capacity, hydraulic turbines operate at off-design conditions with a high number of start and stops. In this situation, dynamic loads and stresses over the structure are high, documenting some failures over time, especially in the runner. Therefore, it is important to know the dynamic response of the runner under operation, i.e., natural frequencies, damping and mode-shapes, in order to avoid resonance and fatigue problems. The detection of natural frequencies of hydraulic turbine runners in operation is challenging because they are inaccessible structures strongly affected by the confinement in water.

Strain gauges are used to calculate stresses of hydraulic turbine runners under operation. However, in this paper, the feasibility to use them to detect natural frequencies of hydraulic turbine runners under operation is studied. For this purpose, a large Francis turbine runner (444 MW) was instrumented with several strain gauges at different positions. First, a complete Experimental Modal Analysis (EMA) of the runner in air was performed using the strain gauges. Then, the natural frequencies of the runner were estimated during operation by means of analyzing accurately transient events or rough operating conditions.

(C) 2017 by the authors. Licensee MDPI, Basel, Switzerland. This article is an open access article distributed under the terms and conditions of the Creative Commons Attribution (CC BY) license (http://creativecommons.org/licenses/by/4.0/). 